\title{
Evaluación de diferentes sustratos en la alimentación de la lombriz roja californiana (Eisenia foetida) a
} efectos de mejorar su producción

Evaluation of different substrates used in the feeding of californian red worm (Eisenia foetida) to improve its production

\author{
Vicente M. Castañeda Chávez ${ }^{1}$ (D), Alex L. Guivin Guadalupe ${ }^{1} \mathbb{D}$, Erik Cuzco Mas ${ }^{1 *}$
}

\section{RESUMEN}

El objetivo del estudio fue evaluar los efectos de algunos sustratos utilizados en la alimentación de la lombriz roja californiana (Eisenia foetida) a efectos de mejorar su producción. La investigación se llevó a cabo por el método experimental con nueve tratamientos y tres repeticiones, dispuestos en un diseño completamente al azar. Los sustratos utilizados fueron: estiércol de vacuno, estiércol de cuy, estiércol de gallina, pluma y sangre bovina. El trabajo se ejecutó en 60 días del año 2018 en la Estación Experimental Agrícola de Chachapoyas, de la Universidad Nacional Toribio Rodríguez de Mendoza (UNTRM) de Amazonas (Perú). Los resultados demuestran que al utilizar los sustratos en mención en la alimentación de la lombriz se pueden lograr mejoras en lo concerniente al peso corporal, la densidad poblacional y el contenido proteico de la harina, lo que no se podría afirmar en lo concerniente a la composición química del compost cuyos resultados son inferiores a los logrados en otros trabajos similares. En conclusión, se podría afirmar que los parámetros productivos relativos al peso corporal, la densidad poblacional y el porcentaje proteico de la harina aumentan o disminuyen de acuerdo al tipo de tratamiento utilizado.

Palabras claves: sustratos; densidad poblacional; análisis bromatológico; harina de lombriz.

\begin{abstract}
The objective of the study was assess the effects so some substrates used in the feeding of the Californian red worm (Eisenia foetida) for the purpose of improving its production. The research was conducted by the experimental method with 9 treatments and 3 replications, arranged in a completely randomized design. Used substrates were: manure of cattle, manure of Guinea pig, manure of hen; feather and bovine blood. The work was carried out in 60 days in the year 2018 at the Agricultural Experimental Station of the Toribio Rodríguez de Mendoza National University (UNTRM) in Chachapoyas, Amazonas-Peru. The results show that the used substrates under study can improve achievements in parameters such as body weight, population density and protein percentage of worm meal. However, with regard to the chemical composition of the compost the results were lower than those achieved in similar works. In conclusion, it could be argued that the productive parameters relative to body weight, population density and the protein percentage of the flour will increase or decrease according to the type of treatment used.
\end{abstract}

Keywords: substrates, population density, bromatologic analysis, worm meal. 


\section{I.INTRODUCCIÓN}

Paco et al. (2011), mencionan que la lombricultura hoy en día es una actividad alternativa que se orienta, por un lado, en la producción de lombrices, y por otro, en el tratamiento de residuos orgánicos para su reciclaje en forma de abonos y proteínas. Este último concepto es de gran importancia cuando de sostenibilidad se trata, ya que se está haciendo uso de material en descomposición (animal o vegetal) para la producción de humus, el cual desempeña un papel fundamental en la restauración de los suelos. Asimismo la lombriz se convierte en fuente de alto valor proteico para la alimentación de animales.

La gran producción de desechos orgánicos (estiércol) producidos por los diferentes sistemas de producción animal, se ha convertido en un problema a largo plazo, en el que se han visto perjudicados por la contaminación, principalmente en ríos y aire. Por tal razón, dentro de las muchas estrategias que se han encontrado para mitigar esta problemática y contribuir a la reducción del uso de fertilizantes utilizados para la agricultura, existe la lombricultura (Bravo et al., 2018).

La Eisenia foetida forma parte de las herramientas biotecnológicas actuales para el reciclaje de desechos orgánicos, obteniéndose como beneficio el abono orgánico "vermi-compost", y carne, fuente óptima para la alimentación animal. Este anélido caracterizado por ser hermafrodita puede llegar a producir grandes cantidades de lombrices por año. El abono producto de sus deyecciones contiene una gran riqueza bacteriana, desarrollando su ciclo biológico en pequeños espacios, y se adapta a un amplio rango de condiciones edafo-climáticas (Loza et al., 2010).

Con referencia a la alimentación, se puede decir que las lombrices se alimentan con cualquier tipo de sustancia orgánica que haya superado su estado de calentamiento. Las lombrices respiran por la piel por lo que la producción de calor y gas metano en la etapa de fermentación les podría causar daños.

Los sustratos son el alimento suministrado a las lombrices para su transformación en residuos sólidos orgánicos por medio de la digestión y la obtención final de humus y de proteína animal.

El pH del sustrato es un factor importante que determina la presencia o ausencia de las lombrices. Garrido (2014) menciona que el $\mathrm{pH}$ debe estar en un rango de 5,5 y 8,0 . Otros expertos consideran que el $\mathrm{pH}$ ideal debe fluctuar entre 6,8 y 7,2. La acidez influye directamente en la alimentación y la reproducción de la lombriz.

\section{MATERIA Y MÉTODOS}

La investigación fue llevada a cabo en la Estación Experimental de Chachapoyas de la UNTRM en el año 2018 , en una área plana de $12 \mathrm{~m}^{2}$ techada con calamina y cuyo entorno se cubrió con manta para evitar las corrientes de aire. En este área se colocaron 27 cajones de madera con una dimensión de $0,5 \times 0,3 \times 0,25 \mathrm{~m}$, lo que correspondió a $0,038 \mathrm{~m}^{3}$ de volumen por cajón. Del volumen total se utilizó $0.023 \mathrm{~m}^{3}$ en cada cajón. El experimento duró 60 días habiéndose colocado 185 lombrices en cada cajón. En total se utilizaron 5000 lombrices en la siembra inicial.

La investigación se realizó mediante el uso del método experimental con nueve tratamientos y tres repeticiones dispuestos en un diseño completamente al azar. Los cajones se colocaron sobre piso de tierra y se cubrieron con una manta arpillera, para evitar la entrada de animales e insectos y de este modo favorecer el flujo de aire.

Los sustratos orgánicos utilizados en los tratamientos fueron estiércol de ganado vacuno, estiércol de gallina, estiércol de cuy, sangre de vacuno y plumas. Los sustratos fueron colocados en los cajones considerándose los tratamientos que se describen a continuación: T1: Estiércol de vacuno (100\%).

T2: Estiércol de vacuno (50\%) + sangre bovina (50\%).

T3: Estiércol de vacuno $(33,34 \%)+$ sangre bovina $(33,34 \%)+$ pluma $(33,34 \%)$.

T4: Estiércol de vacuno $(33,34 \%)+$ estiércol de gallina $(33,34 \%)+$ estiércol de cuy $(33,34 \%)$.

T5: Estiércol de vacuno (25\%) + estiércol de gallina $(25 \%)+$ estiércol de cuy $(25 \%)+$ sangre bovina $(25 \%)$. 
T6: Estiércol de vacuno $(20 \%)+$ estiércol de gallina $(20 \%)+$ estiércol de cuy $(20 \%)+$ sangre bovina $(20 \%)$ + pluma $(20 \%)$.

T7: Estiércol de cuy (100\%).

T8: Estiércol de cuy (50\%) + sangre bovina (50\%).

T9: Estiércol de cuy $(33,34 \%)+$ sangre bovina $(33,34 \%)+$ pluma $(33,34 \%)$.

A los sustratos se les dejó reposar por un lapso de dos semanas antes de colocar las lombrices. Esto se hizo con el fin de proveer las condiciones adecuadas para la adaptación de las lombrices y así mismo simular el tipo de manejo usualmente realizado para este tipo de explotaciones (Schuldt et al., 2007).

Se utilizaron 185 individuos por $0,023 \mathrm{~m}^{3}$ de material fresco en cada uno de los cajones con una densidad total de 5000 individuos adultos de E. foetida. En el momento de seleccionar los individuos, se tuvo en cuenta el tamaño y la presencia de la estructura o anillo clitelar desarrollado, lo cual es indicativo de su capacidad reproductiva. Schuldt et al. (2007) mencionan que el anillo clitelar está desarrollado cuando el individuo alcanza aproximadamente $\operatorname{los} 0,25 \mathrm{~g}$ de peso, independientemente de la dieta suministrada.

Durante la investigación se verificó la humedad mediante el método descrito por Díaz (2002), el cual consiste en comprimir un puñado del material con la mano y comprobar queestando suficientemente húmedo, no suelte agua. En este caso la humedad corresponde aproximadamente a un $70-80 \%$. Esta condición provee un ambiente adecuado tanto para el desarrollo de las lombrices como para la descomposición de los materiales utilizados.

Las mediciones de peso de los individuos se realizaron al inicio, a los 30 días y a los 60 días (final). Para ello se usó una balanza marca UWE, modelo HGM-2000, capacidad de $2 \mathrm{~kg}$ con $0,10 \mathrm{~g}$ de error. Para la obtención de la harina de lombriz se siguieron los siguientes pasos:

- Cosecha: actividad que se realizó por medio de la separación manual de las lombrices de su medio de cultivo.

- Prelavado y lavado: que consistió en la elimina- ción de los restos de compost de las lombrices con chorros de agua.

- Beneficio: consistió en el sacrificio de las lombrices $(100 \mathrm{~g})$ exponiéndoles directamente a los rayos del sol durante cinco minutos.

- Secado: Se realizó en una estufa universal de marca UN55 a una temperatura de $60^{\circ} \mathrm{C}$ por un periodo de 24 horas.

- Trituración de la muestra: se realizó en un molino de cuchillas marca RETSCH, modelo GM 200 con una capacidad de 0,7 litros.

El análisis bromatológico de la harina de lombriz se llevó a cabo con una cantidad de 100 gramos en fresco por cada tratamiento con el objetivo de determinar los siguientes parámetros: Humedad, Ceniza, Fibra cruda, Extracto etéreo, Proteína y ELN. Para lo cual se hizo uso del método AOAC (2016), códigos 92509, 942.05, 978.10, 920.39, 976.05-ISO-Alimentos para Animales y 5983 y 923.03, respectivamente. Para el cálculo del contenido de proteína y determinación del nitrógeno se utilizó el método Kjeldahl.

El análisis químico del compost para determinar el porcentaje de materia orgánica y nitrógeno utilizó el método de Walkley y Black. Para la determinación de fosforo (ppm), el método de Olsen modificado. Además, para la determinación de potasio (ppm), se utilizó el método de saturación con acetato de amonio $1 \mathrm{~N}$ $\mathrm{pH} 7,0$, y para la determinación de calcio y magnesio, el método del acetato de amonio $1 \mathrm{~N} \mathrm{pH} \mathrm{7,0.}$

\section{RESULTADOS Y DISCUSIÓN}

De acuerdo a los datos de la Figura 1, se puede deducir que el peso de la lombriz va en aumento a medida que se incrementa la densidad poblacional. Según Schuldt et al. (2007), las condiciones ambientales son esenciales para el buen desarrollo de la densidad y peso poblacional, siendo los principales factores limitantes la temperatura, el pH, la humedad y la densidad de lombrices que soporta el cultivo. En todo caso el T4 logró un peso superior a los $235 \mathrm{~g}$ a los 30 días y al finalizar los 60 fue superado por el $\mathrm{T} 1$ con un peso mayor a los $328 \mathrm{~g}$. 


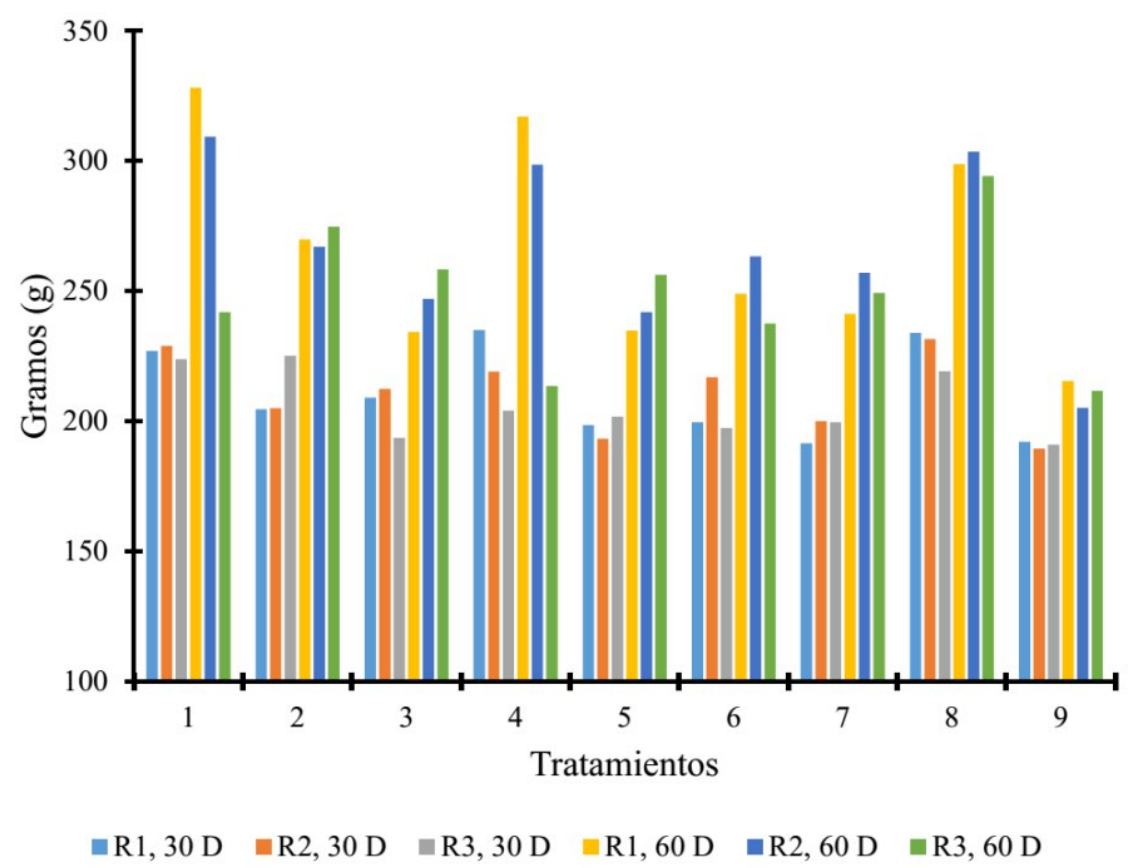

Figura 1. Variación del peso poblacional a los 30 y 60 días por cada repetición y tratamiento.

La figura 2 muestra las variaciones de la densidad poblacional. Así el T1, a los 30 días muestra una densidad de 396 lombrices, superando a los demás trata- mientos. Al finalizar los 60 días llega a 666 lombrices, secundado por los tratamientos 4 y 7 que alcanzaron las 613. La cantidad inicial fue de 185 lombrices sembradas y el sustrato del T1 fue estiércol de bovino.

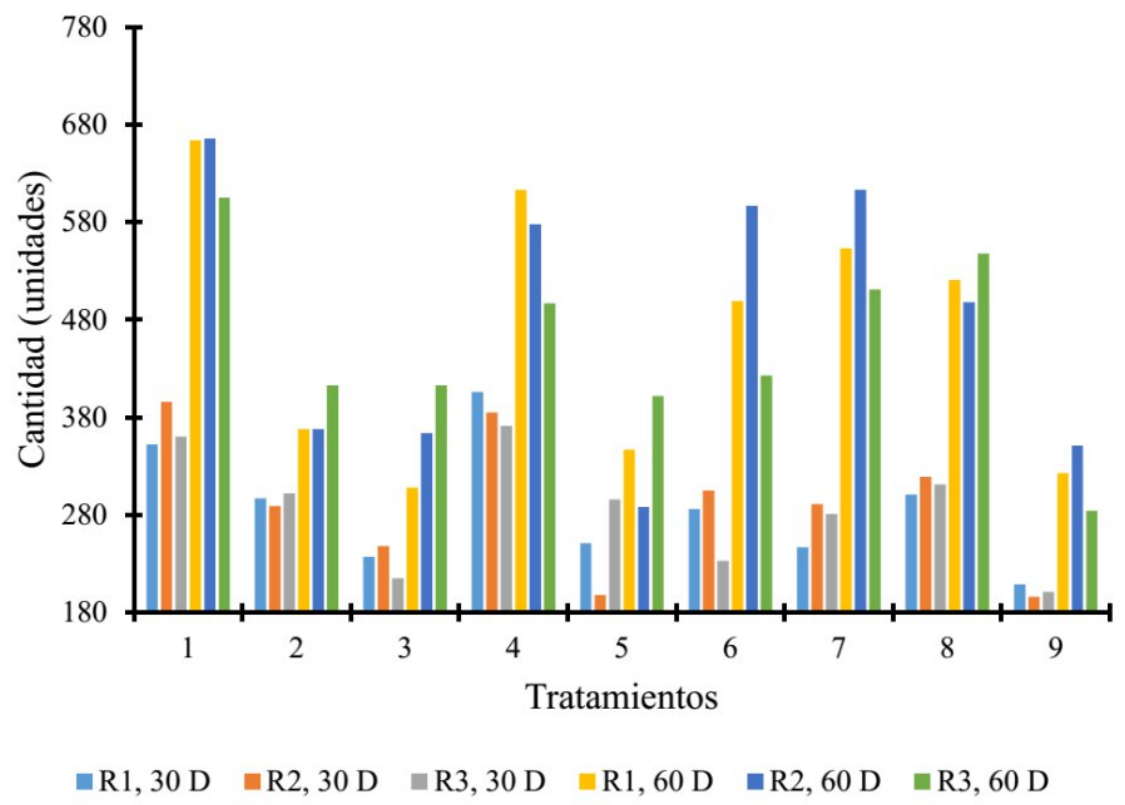

Figura 2. Variación de la densidad poblacional de las lombrices.

La figura 3 muestra los resultados del análisis bromatológico de la harina de lombriz. El T6 alcanza un $51,79 \%$ de proteína superando ampliamente a los tratamientos 2, 3, 4 y 5. El estrato del T6 se compuso de estiércol de bacuno+estiércol de gallina+estiércol de cuy+sangre de bovino y pluma. El porcentaje obtenido es similar a lo logrado por Salas-Dávila (1996) pero inferior a lo logrado por García et al. (2005), que llegaron al $63,8 \%$. 


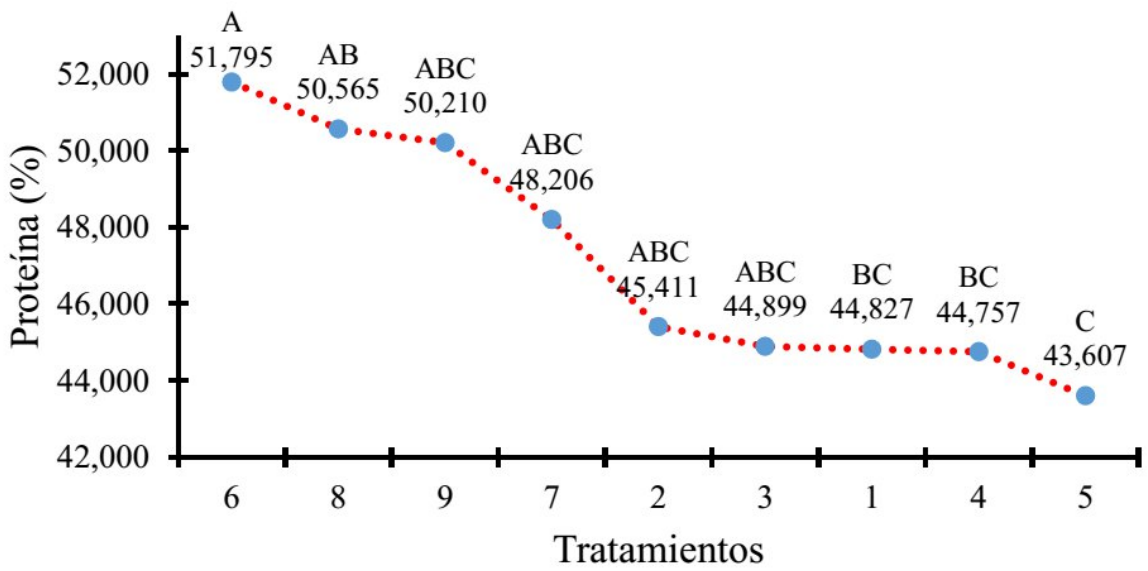

Figura 3. Comparaciones de proteína por tratamiento.

La figura 4 muestra los resultados del análisis químico del compost. El T7 muestra un nivel de $12,41 \%$ de materia orgánica, lo cual es muy inferior a lo logrado por Valenzuela et al. (1998) y Melgarejo et al. (1997), cuyos promedios fueron de $21,99 \%$ y $26,35 \%$, respectivamente

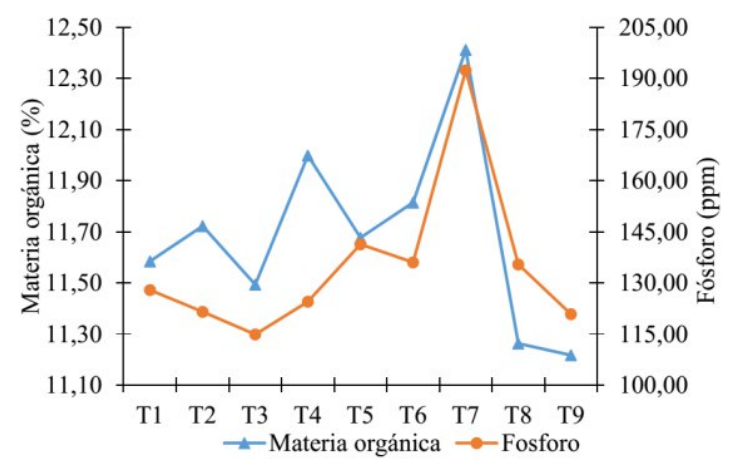

Figura 4. Comparación de materia orgánica vs fósforo del compost.

Igualmente, en lo concerniente al incremento de nitrógeno (Figura 5) el T7 alcanza un pico de 0,62\%. En los nueve tratamientos encontramos un rango que va del $0,52 \%$ al $0,62 \%$ de incremento de nitrógeno, lo que resulta ser muy inferior al obtenido por Castillo et al. (2000) cuyos porcentajes llegan a 1,25\%.

\section{CONCLUSIONES}

La producción de lombriz roja californiana se ha visto considerablemente influenciada por el tipo de sustrato utilizado en la alimentación, ya que se observa que la mayor combinación de estos dio como resultado la disminución de los parámetros productivos. El T1

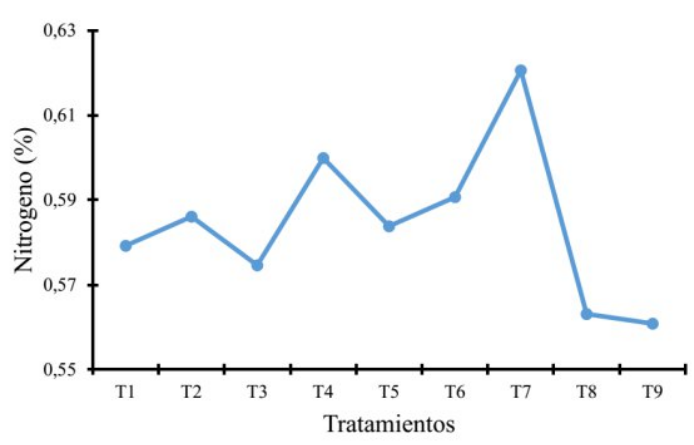

Figura 5. Porcentaje de nitrógeno.

logró un incremento de hasta un $72,2 \%$ en lo concerniente a densidad poblacional.

Los resultados logrados en los tratamientos en estudio con respecto al peso, la densidad poblacional y el porcentaje de proteína en la harina son parecidos a los obtenidos por otros trabajos similares. El T6 logró alcanzar un máximo de $51,79 \%$ de proteína.

Los porcentajes de materia orgánica y nitrógeno $(12,41 \%$ y $0,62 \%$ para el caso del T7) logrados en los nueve tratamientos son muy inferiores a los obtenidos por otros trabajos similares.

Finalmente se puede concluir que los niveles obtenidos en el experimento son aceptables y recomendables para su uso en la Región Amazonas ya que se podrían incluir en la dieta de animales mono-gástricos. La mayor restricción en esta Región tiene que ver con la falta de infraestructura para un adecuado desarrollo de la lombricultura. Para ello será necesario cambiar el sistema tradicional extensivo de crianza por uno intensivo en razón a que el estiércol es la principal fuente de 
alimentación de las lombrices.

\section{REFERENCIAS BIBLIOGRÁFICAS}

Bravo, C. M., L. M. Angulo, Y. A. González, M. M. Martínez, J. C. Carmona, y O. V. Garay. 2018. "Evaluación reproductiva de la lombriz roja californiana (Eisenia foetida) alimentada con diferentes sustratos en el trópico bajo colombiano." Livestock Research for Rural Development 30 (2).

García, M. D., L. Oruña, H. Domínguez, y V. Martínez. 2005. "Evaluación de la calidad proteica de harina de lombriz (Eisenia foeti$d a)$ en ratas en crecimiento." Revista Cubana de CienciaAgrícola 39 (3): 333-338.

Loza, M., B. Choque-Mamani, H. Pillco-Tancara, D. Huayta-Tintaya, I. Chambi-Osorio, y B. Cutili-Palero. 2010. "Comportamiento de lombriz roja californiana y lombriz silvestre en bosta bovina y rumia bovina como sustrato". Revista mexicana de ciencias agrícolas 1 (4): $555-$ 565.

Melgarejo, M. R., M. I. Ballesteros, y M. Bendeck. 1997. "Evaluación de algunos parámetros físico-químicos y nutricionales en humus de lombriz y composts derivados de diferentes sustratos." Revista Colombiana de Química 26(2): 11-19.

Paco, G., M. Loza-Murguía, F. Mamani, y H. Sainz. 2011. "Efecto de la Lombriz Roja Californiana (Eisenia foetida) durante el composteo y vermicomposteo en predios de la Estación Experimental de la Unidad Académica Campesina Carmen Pampa." Journal of the Selva Andina Research Society 2 (2): 24-39.

Schuldt, M., R. Christiansen, L. A. Scatturice, y J. P. Mayo. 2007. "Lombricultura. Desarrollo y adaptación a diferentes condiciones de intemperie." REDVET. Revista electrónica de Veterinaria 8 (8): 1-10.

Valenzuela, O. R., V. H. Lallana, y A. Guerrero. 1998. "Caracterización física y química de lombri- compuestos originados a partir de residuos de conejeras, estiércol vacuno y residuos domiciliarios." Revista Cientifica Agropecuaria 2 (1): 45-48. 